\title{
A Variation Theory Approach to Teaching Calendar Time in Swedish Preschool
}

\author{
Camilla Björklund \\ University of Gothenburg, Sweden
}

\begin{abstract}
Swedish preschool has implemented a revised curriculum since the year 2011. The revision brings a stronger focus on literacy, mathematics and natural sciences as pedagogical content in early years' education, giving the preschool teachers an extended responsibility for children's early education. Yet, the curriculum and tradition in preschool highly values children's interests and flow of ideas, thematic work and play as part of early childhood education. The consolidation of children's perspectives, play and goal-oriented learning in pedagogical practices is the main purpose in early childhood education, according to the national guidelines. The Swedish preschool teacher is thus standing before great pedagogical challenges where their pedagogical content knowledge is put to the test. This issue has been addressed in a developmental empirical project which results are presented in this paper. The purpose is to analyze a designed teaching act in Swedish preschool, to discuss the possibilities for challenging children's conception of calendar time through the pedagogical frames of Variation theory of learning. The discussion extends our knowledge of this particular content in early childhood education and highlights the opportunities to stimulate learning, through a theoretical analysis of both the children's conceptual knowledge and their response to the teaching act related to this content.
\end{abstract}

\section{Introduction}

Early childhood experiences and environment has according to several international studies great impact on children's opportunities to learn and develop both social and academic skills [1]. There are strong voices on the necessity of offering a stimulating environment for young children to facilitate learning in the early years, different from education in lesson-based school environment. Accordingly, one critical and challenging question in early childhood education (ECE) is how to accomplish a goal-oriented practice where children's initiatives and ideas are taken into account and as departure for developmental interaction and planned education. The Nordic countries stress these issues in recently revised curriculum for ECE (see the Core
Curriculum for Swedish preschool [2]) where children's initiatives, interests and flow of ideas should be taken as points of departure when planning for education in early years. Still there are knowledge areas that children are to become acquainted with and develop their understanding of, even though the curriculum only gives guidelines for the work and content in the form of goals to strive for, not goals to achieve at certain levels or ages. In a recent revision of the Swedish curriculum, literacy, mathematics and natural sciences are knowledge areas that are emphasized more than in earlier guidelines. Yet, these areas should be considered as learning objecttives in thematic and integrated education with great respect for children's perspectives. This calls for attention to the teachers' approaches to learning and teaching and how to facilitate goal-oriented learning in a child-centered practice.

Children in preschool encounter a diversity of phenomena during the day that may fall in the category of mathematics, natural sciences and literacy skills. Time is one phenomenon that involves every one of us, including children. However, time is a very complex phenomenon and challenging to get a grip on, due to its subjective form of experiences and various ways of representations. In this study, time represented in calendars is chosen as a learning objective in a designed teaching act, and more specifically the representations of calendar time in weekdays are made object of learning in a Swedish preschool context with 5-year-olds. The aim is to discuss the possibilities to challenge children's conception of calendar time through designed learning sessions based on specific theoretical conjectures of the nature of conceptual learning and teaching in early years.

\section{Concepts of time $-\mathbf{a}$ brief history}

The concept of time has inspired many philosophers across the world for a long time. It is said that ever since human kind became aware of the own self and confronted the surrounding world and its constant change, it has been a necessity to describe and try to understand the present, the past and the future. Calendars are an expression of this need that can be found in most cultures and early civilizations.

The idea of duration and the flux of time have over the last two thousand years been defined in 
different ways, more or less compatible with everyday life. Jammer [3] describes these ideas beginning early on with the Pythagoreans who divided time into measurable units such as days, weeks or months which delimited time's flow. Aristotle separated time from space and argued for time being the measure of motion, with respect to movement before-and-after. Galileo introduced on the other hand time as linear, adding a geometrical dimension independent of motion but a descriptive variable for measuring motions, accelerations and other physical phenomena. These assumptions are separating a physical concept of time from a perceived notion of time, a troublesome issue addressed by Locke and Berkeley who claim that any knowledge is connected to the experiences and consciousness of one self, which means that time is a relative, subjective and private occurrence. This leads in turn to Leibniz who argues for a quite modern idea that time is the order of such things that are not existing simultaneously. This latter idea is also recognized in Einstein's early writings about time being propositions about simultaneity.

Competences related to the conception of time are usually associated with measurement and reading of calendars and timelines. Augusto [4] discusses the idea of time structure, and visualizes the concept of time as how its structure is conceived. As a contrast to linear time he presents the idea of circular time structure and how time is conceived as a whole. Questions that are raised by this idea are for example if all parts of the structure are exactly the same? Are the parts connected to each other and related to a sequence? Is the structure symmetrical that is if the structure looks the same independently of direction? Considering the calendar with months and weeks we realize that the parts of the whole are in fact not exactly the same. The very concept of time is thereby very complex and so are the many ways of representing time. It is thus not surprising that time and calendars are considered a difficult content for children to develop their understanding about [5].

\section{Children's conceptions of time}

Most research on children and the conception of time focus on the notion of time durability. Murray [6] investigates for example conservation aspects of the concept of time in primary school children with experiments of variations in height, transformations of appearance, moving hands on clocks or toy trains in motion. Later research also follows the same idea investigating time as duration related to motion, duration as a personal experienced phenomenon [7] or the order of sequences in pictures [8], in many ways following the footsteps of Piaget.

Piaget [9] studied children's conception of time and describes the development starting from the age of four when children have acquired sufficient language abilities. At this age the concept of time is considered merely intuitive due to children's nonreversible features of thought. That is, children are supposed not to be able to relate what is happening now to what has happened before and what will happen in the future. In later years (approximately 810-year-olds) children may, according to Piaget, develop this ability and are able to link past events to present and future events as a linear sequence. Piaget claims that such a cognitive development cannot be invoked by teaching. Yet, there are according to Burny et.al. [5] a number of research reports that give credence to cultural and social impact on the conceptions of time that people develop and the role of instruction should thereby not be underestimated.

Children's acquisition of the concept of time and reasoning skills on time-related issues are not developing in isolation. These skills rely according to Foreman et.al. [10] on children's abilities to reason about numeracy, literacy, memories and space, among other. Kelly et.al. [11] have for example shown that linguistic structures have impact on individuals' skills of calculating with calendars, where for instance Chinese names of days and months are structured on a numerical base. English names of days have not the same obvious base, which have impact on the fluency with which children may work on a calendar. Also the Swedish names for weekdays derive from ancient mythological gods and the names of the months from Latin names of planets and gods as well as Latin number names, with limited clues on order and number.

In education the timeline is a common representation that can be recognized in academic subjects such as history, geography and mathematics. Those who have studied the concept of time conclude that the only way for the human mind to understand time is to find ways to represent it as cognitive maps associated with environmental cues [8]. Other experimental studies [12] also give credence to the idea that children are able to estimate duration of time better if they can relate the elapsed time to some quantified cues, for example counting on the number rhyme or regular taps on a drum. However, several studies by Pramling [13] show that children who are engaged in educational work aiming for example at teaching the notion of time through visual representations, does not necessarily develop conceptual understanding of said notion. It is thus not always the case that concrete action will develop conceptual understanding on a more general level.

Kelly et.al. [11] state that calendar reading is known to be a task that children do not acquire easily. Sub-competencies that are relevant for reading and interpreting a representation such as the timeline is ordering in sequences, linguistic skills and a visuospatial ability. Further the children need to develop a conceptual sense for the phenomenon time that the timeline is representing, which includes a sense of 
duration and a personal experience of the relation between intervals.

According to Friedman [14] most preschool children (age 4-6) can recite events of the day or seasons. Friedman defines the development of calendar reasoning skills as depending on two models, the first one is to recite the days of the week as a list of names and reasoning is connected to the closeness of the names within the list. The second model is an image-based conception of temporal structure that enables the individual to comprehend days within the week as related spatially, which allows a more direct access to the parts of the whole. This latter image system emphasizes a cyclic structure where continuum is an essential notion. In Friedman's study, most of the children in $2^{\text {nd }}$ grade had difficulties in reciting the days beginning with an interior day. This lack in conceptual understanding may be compared with how children learn to count, where one important aspect is the stabile order of number words and that you can start or continue counting from any number [15]. The experience of a unit as part of a whole is thus important for developing the concepttual understanding of such abstract ideas as number as well as calendar time.

As history tells us, time is not a simple issue to define, understand and relate to. At the same time, we as human beings tend to organize our day in suitable intervals, often conceptualized with connection to changes in environmental phenomena or events. The problem addressed in this study is not how children experience or learn about duration of time or to recite the weekdays. The pedagogical problem is rather how children experience and perceive time as it is represented in a structure of weekdays and how to facilitate conceptual understanding of this particular phenomenon.

\section{Theoretical frame for studying learning and teaching}

Implementing the revised curriculum for preschool in Sweden implies a practice where the teacher's theoretical knowledge (both subject matter knowledge and pedagogical content knowledge) and children's experiences are plaited together. A phenomenographical approach to children's learning and knowing about their surrounding environment and the variation theory of learning brings a unique opportunity to develop and conduct such a practice. This approach to ECE is described in other terms as "developmental pedagogy", a theory and practice orientation that has been tested in many empirical research studies and pedagogical practices [16].

Phenomenography is an approach to understand people's experiences and the phenomenon learning and understanding. The purpose is to explore variations of conceptions among people sharing experiences of a specific phenomenon [17]. It is assumed that there is only one existing world (a non-dualistic ontological approach) which is experienced in qualitatively different ways by people. This means that learning is considered as changes in seeing the world, depending on earlier experiences as well as experiences offered in a specific situation. Asking for peoples' experiences and conceptions of some phenomena is thereby of pedagogical interest, in order to figure out which aspects or experiences that are not yet being discerned by the learner. This theory of learning has in later years developed into the Variation theory of learning, described in more details below.

By tradition, the idea of asking a person for his or her experiences as a departure point for pedagogical planning, is considered of utmost importance in the work with young children in Sweden. But this is also a great challenge especially for teachers interacting with children not yet verbally skilled, but expressive in many other ways. Asking for the child's perspective on some common object of learning is of today's ECE in the Nordic countries a well-established strategy for developing children's understanding. However, there are other challenges that teachers in preschool encounter once they learn about children's understanding and experiences of a given learning objective. These challenges concern the teaching of a specific learning object. In phenomenographical terms, the teaching act should offer experiences that will broaden the ways in which the learner sees the world.

Variation theory has developed during the last two decades from an extensive research on variations of conceptions (the phenomenographic approach). Questioning the fact that people may have different understanding of the same concept depending on their earlier experiences has driven the theoretical discussion to describe learning and understanding as ways of experiencing a certain phenomenon. A learning situation may contain more or less opportunities to discern critical features of the phenomenon in question. Development in understanding is thus considered, according to this theoretical approach, to become able to discern several and various features or aspects of a phenomenon simultaneously [18]. This theory has great impact on pedagogical settings, as teaching and learning can be described and analyzed in terms of discernment, variation, critical features and the object of learning as intended, enacted or lived [19].

The variation theory approach gives support also to early childhood goal-oriented practice in the act of discerning what features and aspects that are made visible for the learning child (the enacted object of learning), and what is yet undiscerned. As Pramling Samuelsson and Asplund Carlsson [16] say, ECE is about making what is invisible visible. Everyday phenomena and notions used in daily communication should be problematized and made object of lear- 
ning, as any notion or phenomenon may be comprehended in qualitatively different ways. A shared focus is thus important for communicating about common meaningful phenomena as well as for developing understanding into more complex and abstracted comprehension. This sets another challenge to the preschool teacher, as teacher training for early years in the Nordic countries are very broad and only in recent years have brought in the stronger focus on content knowledge and skills in different academic fields. The preschool teacher is in this respect responsible for the youngest children's academic, social as well as aesthetic education, though having limited training in each area.

Empirical research give support to the positive effects of developmental projects where variation theory is considered to build a frame for both understanding the core of a learning object and facilitating children's learning, which will be the topic for discussion also in this paper.

\section{The project - aim and methods}

Swedish preschool has from July $1^{\text {st }} 2011$, implemented a revised curriculum for education in early childhood. This curriculum sets goals to strive for, but do not express goals to achieve and assess at certain levels, as in compulsory school. Objectives that preschool is obliged to work with are quite broad and focus on competencies more than factual knowledge. For example is one goal formulated as "[the children are] to develop their skills to differentiate shades of meaning in concepts, as well as to see interconnections between concepts and thereby discover new ways of understanding their surroundding world" [2]. There are also goals with objectives more specified for example within the area of mathematics and natural sciences. One can read in the curriculum that preschool should support children's developing understanding for measurement, time and change, among other objectives. It is up to the teachers to further break down the content into comprehensible learning objects that is suitable to work with according to the needs and experiences of the children. There is a long tradition of thematic work in Swedish preschools, along with integrated play and learning, which is also accentuated in the curriculum as a suitable way to educate and teach in the early years.

The authentic example in this paper derives from a project during spring 2012, in Swedish preschool settings (children 5 years old). Three preschool teachers take part in an in-service program designed as a Learning Study [18]. The object of learning is calendar time, represented in models of the week (Monday-Sunday). This theme is very common in Nordic preschools but is also considered one of the most difficult learning objectives. The Learning study design is based on the conjectures outlined in the Variation theory of learning. The design thereby includes a cycle of scrutinizing the intended object of learning, how children understand the learning object, which aspects that may be critical to discern in order to understand the learning object in the intended way and a plan for how to facilitate discernment of specific aspects. This plan is carried out by the teachers in their child groups. The teachers mainly work with smaller groups of children at a time (4-7 children) in planned activities where the children are encourage to participate, interact, take initiatives and express themselves in various ways. In this way, the teachers will gain knowledge of the children's current conceptions and which aspects that seem critical to explore for further development. Each session lasts 10-45 minutes and is documented with video. The sessions are carefully evaluated based on the teachers' interpretations of learning outcomes expressed through children's verbal and non-verbal actions. Each utterance or action is considered as an expression of the child's understanding which will give the teacher a point of departure for further planning of teaching acts. The Learning study cycle then starts again in a cooperative learning process involving the participating teachers and the researcher. While scrutinizing the concept of calendar time based on the children's responses and the common representations earlier used in education, the teachers develop their own understanding of children learning about this concept and also learn to organize for situations where children are offered opportunities to further explore the features of the concept.

Reflection-in-action is essential if teachers will be able to hold on to and develop the opportunities that arise during any teaching act in preschool. This calls for extensive skills of reflection-in-action, as Schön [20] describes one aspect of professional skills in education. However, to reflect in action, one has to have reflected on action. In this particular study we strive for reflection through stimulated recall dialogues with video-documentations of the conducted learning sessions. Focus for reflection and analysis is the enacted object of learning and how children respond to the teaching act.

The main aim of the study is to analyze possibilities to challenge children's conception of calendar time by analyzing the enacted object of learning in designed learning sessions. Of specific importance in the empirical project is facilitating conceptual development through child-centered and play-based yet goal-oriented education.

\section{Results}

There are many issues that can be discussed with this project as point of departure. The teachers become aware of their own approach to the learning content and intended object of learning as well as the 
children's conceptions and understanding of the same. These were prerequisites for the developmental work but cannot be discussed in detail in this paper. The following presentation is a summary of the extended knowledge of teaching calendar time in preschool, derived from the scrutiny of what it means to learn about this phenomenon and how different ways of enabling certain features to become object of discernment to the children, brings opportunities and limitations to the learning process. Insights are often acquired by the teachers when children's responses and questions bring attention to new undiscerned aspects or different perspectives, directing attention to features critical for developing conceptual understanding.

\subsection{The repetitive aspect of calendar time}

The first issue we found necessary to establish understanding of was the repetitiveness of the weekdays. The common procedure in preschools is that one starts from Monday and recites the days through to Sunday or stops at the current day of the week. If the children are about to understand that the temporal structure of the calendar week is repetitive, it is necessary to recognize the verbal list as an ongoing rhyme. Many children spontaneously begin to recite the weekdays as a rhyme or song when the teachers start talking about the calendar week, but there are also children who are unsure about the rhyme and order of the weekdays. It was thus found important to raise attention to the order of the weekdays and to visualize the transition from the end of the week-rhyme to the beginning of another similar rhyme.

One of the teachers emphasizes the repetitive aspect in a very visual way when she organizes a song and game to which the children actively participate and they themselves are representing the weekdays.

First all 20 children stand in a line, reciting with some help the weekdays, one day per child with a specific attention to what happens when Sunday is presented and the following child will be Monday. When the last child in the line says "Saturday", the teacher steps in to represent "Sunday". She then asks what to do, as "Sunday" also wants a "Monday" by her side. Together they figure out that the first child "Monday" also lacks a second partner by her side. The problem is solved as the last person "Sunday" takes hold on the first person "Monday's" hand and they all form a circle. Here they check the order again and decide that the circle of weekdays is complete. The game continues with a song repeating the weekdays.

The focus on the transition from the end of one week to the beginning of another is highlighted by the fact that there is both a beginning and an end of the line and since the children are representing the weekdays, every unit (weekday) has to have a neighbor. When forming the circle, this critical aspect becomes possible to discern by the children. The circle is an ongoing curve, representative for the abstract idea of time being organized in specific intervals.

Another way of working with the repetitive aspect of calendar time is to start on any given weekday and count on varying numbers of days. The pedagogical goal is in this case to enable discernment of how units in a rhyme are related to each other, emphasizing the part-whole-relationship and the specific order of the units. This was organized through developing a board game with seven steps, one for each weekday and different tasks to perform on each step.

The participants are moving along a path of steps, one weekday for each step in a linear model. When throwing the dice, you move forward as many steps as the dice shows and the teacher and children check which day they started from and which day they end up on. Depending on the weekday they end up on, they will take cards with different tasks and questions to answer. One child stands on Saturday and throws a five on the dice. Another child then asks "what do you do when you come to the end and throw more? Do you go to start again, Monday once more then?" The teacher follows up the question and helps the dice-throwing child move her play mark at the same time she answers "after Sunday comes Monday, the days come again and again" and points at the board game.

The above described examples are ways of working with the same learning object, where the repetitive aspect of calendars is emphasized, yet in different ways. The knowledge acquired through such activities is important, but should not be taken as a guarantee for conceptual understanding. Some children have not yet acquired the week-rhyme as a continuous string of words, which probably is a prerequisite for further exploring the meaning of calendars and the conceptual idea of weekdays. Through these activities, the weekdays per se as well as the repetitive aspect of the weekdays are made possible to discern. This gives though further reason to discuss what is made possible for the children to discern depending on the characteristics of the representational form, for example circular versus linear representations.

\subsection{Circular versus linear representations - the aspect of continuity}

The first attempt to work with this learning object showed great success with representing the continuous and repetitive aspect of the week as a circle, in that the children discerned that something has to follow after "Sunday". The second teacher's board game did however bring in this aspect in a varying 
but equally important way. While moving from one day to another, the children eventually came to Sunday and had to figure out where to go next. As they had been talking about the day after Sunday, the children easily figured out that they had to continue from the beginning of the week/board again. The teacher chose this representation as a transformation clue between the circular investigation of the week progression and the common calendar hanging on the wall where each row starts with Monday and ends with Sunday. In accordance with the variation theory of learning, it is crucial to discern differentiated aspects simultaneously in order for a conceptual development to occur. The children's earlier experiences of the calendar hanging on the wall will probably be given a new meaning after working with the repetitiveness of the weekdays and the different (linear and circular) ways of expressing a week.

\subsection{Emphasizing the part-whole-relation}

The teachers are working with the representations of the weekdays as a whole, where every part (weekday) has its own place and order in the sequence but are constantly related to the other parts and subgroups of this whole. One example of this is a discussion on which days are school-days and which days are weekend, the order of the days are thus critical and emphasized by the teacher who encourage the children to reflect upon "tomorrow", "yesterday" as well as days before or after some specific day. In other words, they are working on a model in multiple directions which enables the children to discern how units are related to each other and the whole. This approach seems to support children's attention to the temporal aspect, that days go by in a stabile order and tempo. This is discerned in one learning session where one teacher uses a circular model of the week, where preschool days are lightly colored and Saturday and Sunday are in darker colors. An arrow marks which day it is and the children are used to discussing about what day it is based on the movement of the arrow each morning.

A great learning opportunity emerges when the children discovers the differences they experience in weekdays and weekends. They are then encouraged to discuss various strategies for moving the arrow as representing Saturday and Sunday. The children express that they are not in preschool at the weekend and thereby not being able to move the arrow every morning as they do on schooldays. The idea of moving directly from Friday to Monday on Monday morning is problematized as well as moving the arrow in advance on Friday afternoon, expressed by some children as "what if someone comes on Friday afternoon and sees that it is moved to Saturday, then he might think it is already Saturday". The representation related to the subjectively experienced phenomenon of time is here highlighted and made object of learning. Critical seems to be the idea of every day as a part of a whole where every part plays a specific role in relation to the other.

The variations in expressions give the teacher an excellent opportunity to discern how the children experience time duration in relation to the temporal representation. These ideas are followed up in the following learning session where they are working with the aspect of progression in time.

\section{4. "Same but different" - progression in calendar time}

When the idea of the calendar week as a repetitive and continuous representation was established among the children, the concept was extended in bringing in the aspect of progression. The children's own experiences and daily activities were taken as starting points and the teachers explored in different ways how the weekdays continued to come and go in equal intervals but time and actions varied. This was the topic for a discussion with the children after an ongoing routine introduced by one of the teachers.

The teacher documented activities that children took part of every day. Together with the children she put up a picture of their activity of the day around the week-circle hanging on the wall. After a couple of weeks they had several circles of pictures around the week, giving them a good starting point for talking about the progression of time. The teacher asks "what do we do on Fridays" and the children respond "we go out in the yard". The teacher asks "what did we do last Friday, can Marvin look at the pictures and tell us?" The child Marvin says "we were out in the yard". Teacher: "what did you do in the yard last Friday?" Marvin says "We built with sand". Teacher: "Are you going to do same thing today?" The discussion goes on about what they do on different occasions that are similar and different, always referring to the week-circle on the wall.

The critical idea that is enabled to discern in this example is that weekdays and calendars in general are just models for time intervals where time is a progressive phenomenon. There will be a Monday every week, but last Monday is not the same as next Monday. Even if the content and activities of the day may be planned to be similar, the children recognize that one point in time will never be exactly the same. This is a very complex idea to grasp and probably contain several dimensions that are not yet discerned by these children. Still, due to the teachers' efforts to visualize the phenomenon both through different (activities) and invariant features (the recurrent names of the days and activities), the children are given reasonable opportunities to make meaning of this complex idea.

The teacher in this example also bring in another dimension of the learning object, the calendar year as 
a large circle with twelve months, to point out the similar idea through variations in representations. This simultaneous discernment turned out to be effective for some of the children, as they could relate to earlier birthdays and forthcoming ones.

\section{Discussion}

Swedish preschool has a long tradition of childcentered practice where free play and children's interests have been strong features. Many teachers adopting this traditional approach make use of representations and plan activities where children are engaged in doing things. The presumptions are usually that when children are engaged in doing, knowledge will follow [13]. Recent attention to learning objectives and the notion of knowledge and meaning-making in early years raise the question of what and how learning is facilitated in ECE. Participating in activities should to be connected to the intentions of the activity, if conceptual learning is to occur. Reciting the week-rhyme is in this respect not an expression of knowledge of time and temporality. This project give insights into two aspects of this pedagogical issue: children experience various things and features while exploring one and same phenolmenon which may in turn have impact on what the child actually learns in a given situation. If the teacher learns to recognize critical aspects of a specific learning object, it is possible to organize for children's learning in goal-oriented, playful and child-centered practices.

The three teachers in this study have been working with the same learning object in their respective child groups. The learning objects were carefully chiseled out and planned for, in that the intended object of learning and necessary aspects would be made possible for the children to discern. The conclusion after the learning study is that a demarcated learning object is important to scrutinize and plan for, as it gives the teachers a way to interpret children's actual understanding of said learning object, as other objects and aspects are excluded, but not forgotten. However, this should not diminish the teachers' sensitivity to the children's intentions and flow of ideas, which is a highly valued aspect of teaching in Swedish early childhood education [2].

In this particular paper, the purpose was to discuss the possibilities of challenging children's conception of calendar time through the pedagogical frames of Variation theory of learning. The teachers are enabling discernment of critical aspects through bringing fore variation within and between aspects of the learning object, in accordance with the theoretical frame. Planned activities that are experienced meaningful and playful to the children are creating opportunities to direct young children's attention to such critical aspects that are necessary to discern. Play, games and everyday experiences are thus con- sidered important pedagogical resources, however, they have to be planned with great care if used in goal-oriented purposes.

The work reported in this paper has extended the body of knowledge of this particular teaching content in early childhood education. The discussion also give guidance to some of the critical features necessary to consider (repetitiveness, continuity, progresssion and part-whole-relationship) when planning for developing children's understanding of calendar time. When these features are emphasized in the teaching act, the probability of conceptual development is high, since the teachers themselves have developed a greater understanding of the content they are teaching and how children may respond to this content.

The pedagogical environment is according to the results of this study much more important for conceptual development than earlier research on this specific content has acknowledged. Friedman's claim [14] that children younger than eight years usually are unable to start calendar counting or reciting from any day within the list of weekdays is thus not recognized in this study and becomes especially evident in the board-game activity where the purpose of the activity enables the children to reason logically about necessary conditions and aspects. One reason for this might very well be the focused instruction and carefully planned teaching activities that direct the children's attention to the continuous aspect of the calendar structure and how days are given a specific order which highlights the relation between the days and even further the wholeness of the week.

The described teaching approach is according to the participating teachers a new way of talking and focusing on the weekdays, which indicates that the focus of instruction, the intended object of learning, has to be clear to the teacher and to the children. It is then apparently possible to facilitate learning even of abstract and quite complex concepts. Even though this project does not assess learning outcomes with tests, development in understanding may be interpreted in the children's responses to the planned activities and enacted learning objects, where they participate and take initiatives to action in more powerful ways during the learning sessions. Piaget would perhaps be surprised to see that it is possible to make meaning of such cognitive structures through carefully planned instructions.

When we learn to discern the possible difficulties or qualitatively different ways of interpreting a concept or notion, we have a better basis for organizing learning situations where children's conceptions are challenged in meaningful ways. This knowledge is valuable especially in pedagogical practices that depart from children's interests and experiences. Making the invisible visible is a great challenge for the preschool teacher, but the theore- 
tical frame of variation theory of learning seems to support teachers in their planning, evaluation and development of goal-oriented but also child-centered practice, due to the emphasis on specific critical aspects and the systematic work on enabling these aspects to be discerned and explored by the children.

The results of the learning study support Kelly et.al. [11] in their description of children needing to develop a conceptual sense for the phenomenon time that the timeline is representing. This conceptual knowledge includes a sense of duration and experiences of the relation between intervals. When children are given opportunities to explore varying ways of understanding these aspects, they are able to reason about the part-whole-relationship, the repetitive, continuous and progressive nature of the calendar structure and also the symbolic idea of representations per se. To fully comprehend the idea of calendar time, these aspects should be fused together as one integrated conception. This is not possible to facilitate in a few weeks of work, but differentiating the critical aspects is an important base for further development and understanding.

Results of this project extend our knowledge of a learning object that is very common in preschool, but also give insight into its extensive complexity. It's a delicate balance between the teacher's intentions and children's focus, in other words the discrepancies between the intended object of learning and the enacted object of learning [19] and also the lived object of learning. Still, the participating teachers seem to be well prepared for the children's spontaneous intentions and shift in focus. One claim is that this preparedness is due to the theoretical discussions on the possible difficulties of understanding the object of learning and a very specific goal towards which they are guiding the young children's attention. There are significant results from comparisons between learning studies and lesson studies that traditionally are undertaken in Japan, which at first glance seem similar, but in a closer analysis reveal significant positive results in learning effects when teaching is planned with an explicit theory of learning as starting point and frame for reflection-inaction, as is the case in this learning study. The most important result is though that it can be made possible, through the scrutiny of the enacted learning object and the learning act within the frames of phenomenography and variation theory, to find ways to organize education where children's perspectives are truly the basis for the progress in interaction towards a specific goal.

\section{Acknowledgement}

The project presented in this paper is funded by the National Research Council in Sweden (project nr. 724-2011-751).

\section{References}

[1] OECD, Starting Strong II. OECD Publishing, Paris, 2006.

[2] National Agency for Education, Core Curriculum for Preschool 98. Revised 2010, 2010.

[3] M. Jammer, "Concepts of time in Physics: A synopsis", Physics in Perspective, vol. 9, 2007, pp. 266-280.

[4] L.C. Augusto, "The logical approach to temporal reasoning", Artificial Intelligence Review, vol. 16, 2008, pp. 301-333.

[5] E. Burny, M. Valcke, and A. Desoete, "Towards an agenda for studying learning and instruction focusing on time-related competences in children", Educational Studies, vol. 35, issue 5, 2009, pp. 481-492.

[6] F. Murray, "Conservation aspects of the concept of time in primary school children", Journal of research in science teaching, vol. 6, issue 3, 1969, pp. 257-264.

[7] A.S. Westman, "Development of time concepts: Differentiating clock and calendar from apparent durations", Journal of Genetic Psychology, vol. 148, issue 3, 1987, pp. 259-270.

[8] R. Actis-Grosso, and D. Zavagno, "The representation of time course events in visual arts and the development of the concept of time in children: a preliminary study", Spatial Vision, vol. 21, issue 3-5, 2008, pp. 315-336.

[9] Piaget, J. The child's conception of time. Routledge \& Kegan Paul, London, 1969.

[10] N. Foreman, S. Boyd-Davis, M. Moar, L. Korallo, and E. Chappell, "Can virtual environments enhance the learning of historical chronology?" Instructional Science, vol. 36, 2008, pp. 155-173.

[11] M. Kelly, K. Miller, G. Fang, and G. Feng, "When days are numbered: Calendar structure and the development of calendar processing in English and Chinese", Journal of Experimental Child Psychology, vol. 73, 1999, pp. 289-314.

[12] F. Wilkening, I. Levin, and S. Druyan, "Children's counting strategies for time quantification and integration", Developmental Psychology, vol. 23, issue 6, 1987, pp. 823-831.

[13] I. Pramling, "Understanding and empowering the child as a learner", in D. R. Olson and N. Torrance, eds., The handbook of education and human development. New models of learning, teaching and schooling, pp. 565-592, Blackwell Publishers, Cambridge, Mass., 1996.

[14] W. Friedman, "The development of children's knowledge of temporal structure", Child Development, vol. 57, 1986, pp. 1386-1400.

[15] K. Fuson, and J. Hall, "The acquisition of early number word meanings: A conceptual analysis and 
review", in H. P. Ginsburg, ed., The development of mathematical thinking, pp. 49-107, Academic Press, New York, 1983.

[16] I. Pramling Samuelsson, and M. Asplund Carlsson, "The playing learning child. Towards a pedagogy of early childhood", Scandinavian Journal of Educational Research, vol. 52, issue 6, 2008, pp. 623-641.

[17] Marton, F., and S. Booth, Learning and Awareness. Erlbaum, Mahwah N.J., 1997.

[18] Marton, F., and A. Tsui, Classroon discourse and the space of learning. Lawrence Erlbaum, Mahwah, N.J., 2004.

[19] U. Runesson, "Beyond discourse and interaction. Variation: a critical aspect for teaching and learning mathematics", Cambridge Journal of Education, vol. 35, issue 1, 2005, pp. 69-87.

[20] Schön, D., The reflective practitioner. How professionals think in action, Arena, Aldershot, 1995. 